\title{
Simplified Calculation for Fire Performance of Post-Tensioned Timber Box Beams
}

\author{
REUBEN COSTELLO, ANTHONY ABU, PETER MOSS and ANDREW BUCHANAN \\ Department of Civil and Natural Resources Engineering \\ University of Canterbury \\ Private Bag 4800 \\ Christchurch 8140 \\ New Zealand
}

\section{ABSTRACT}

This paper describes a simplified calculation method that can be used to predict the fire performance of post-tensioned timber box beams. Despite being a combustible material, timber beams can perform well in fire. However, post-tensioned timber box beams need to be carefully designed if an undesirable shear failure mode is to be avoided. A simplified calculation is proposed which can be used to design these beams while giving the designer the ability to predict when and how the beam is likely to fail. Two beam geometries have been used as examples to demonstrate the ability of this calculation method to predict the likely mode and time of failure. Finally, potential improvements that may be made to the method as well as experimental tests that will be conducted to verify the model are discussed.

KEYWORDS: post-tensioned timber, fire resistance, structural design, structural response, performance-based design

\section{NOMENCLATURE}

$\begin{array}{llll}A & \text { area }\left(\mathrm{mm}^{2}\right) & T & \text { time }(\mathrm{min}) \\ A_{s} & \text { shear area }\left(\mathrm{mm}^{2}\right) & V^{*} & \text { design shear force }(\mathrm{kN}) \\ d & \text { depth }(\mathrm{mm}) & w & \text { width }(\mathrm{mm}) \\ D & \text { depth of beam }(\mathrm{mm}) & \bar{y} & \text { neutral axis depth }(\mathrm{mm}) \\ e & \text { eccentricity }(\mathrm{mm}) & Z & \text { section modulus }\left(\mathrm{mm}^{3}\right) \\ E & \text { elastic modulus }(\mathrm{GPa}) & \text { Greek } & \\ f_{b} & \text { characteristic bending stress }(\mathrm{MPa}) & \beta & \text { char rate }(\mathrm{mm} / \mathrm{min}) \\ f_{c} & \text { characteristic compression stress }(\mathrm{MPa}) & \delta & \text { deflection }(\mathrm{mm}) \\ f_{s} & \text { characteristic shear stress }(\mathrm{MPa}) & \Delta & \text { change in } \\ G & \text { shear modulus }(\mathrm{MPa}) & \varphi & \text { strength reduction factor } \\ G^{*} & \text { dead load }(\mathrm{kN} / \mathrm{m}) & \text { subscripts } \\ I & \text { second moment of area }\left(\mathrm{mm}^{4}\right) & c & \text { compression } \\ I_{c c} & \text { local second moment of area }\left(\mathrm{mm}{ }^{4}\right) & f & \text { flange of beam } \\ k_{1} & \text { load duration factor } & f, \text { bottom } & \text { bottom flange of beam } \\ k_{8} & \text { stability factor } & f, \text { top } & \text { top flange of beam } \\ k_{24} & \text { size factor } & h & \text { hole in beam } \\ L_{B} & \text { span of beam }(\mathrm{m}) & i & \text { time step i } \\ M^{*} & \text { design bending moment }(\mathrm{kNm}) & P T & \text { post-tensioning } \\ N^{*} & \text { design axial force }(\mathrm{kN}) & q & \text { uniformly distributed load } \\ P T^{*} & \text { post-tensioning force }(\mathrm{kN}) & t & \text { tension } \\ q & \text { uniformly distributed load }(\mathrm{kN} / \mathrm{m}) & V & \text { shear } \\ Q & \left.\text { first moment of area }(\mathrm{mm})^{3}\right) & w & \text { web of beam } \\ Q^{*} & \text { live load }(\mathrm{kN} / \mathrm{m}) & x & \text { individual section of beam } \\ t & \text { thickness (mm) } & 0 & \text { initial conditions } \\ & & & \end{array}$




\section{INTRODUCTION}

Timber is an organic material that has been widely used as a construction material throughout human history due to its high stiffness and strength-to-weight ratio and the relative simplicity with which it can be used [1]. Timber is also widely regarded as a sustainable material, especially when compared to other construction materials such as steel and concrete. These factors have led to an increased use of timber as a structural material in recent years.

\subsection{Fire performance of timber structures}

A potentially significant disadvantage of timber is the fact that it is a combustible material. As a result of its combustibility the use of timber as a building material is heavily restricted by many standards and building regulations throughout the world. Despite these restrictions timber structures can be designed to perform very well in fires. This is especially true for structures that utilise heavy timber construction. When a timber element is exposed to fire a char layer forms which insulates the remaining unburned material, significantly increasing the member's residual fire resistance. Heavy timber structural members can be re-used even after they have been exposed to fire [2, 3]. Figures 1 and 2 show a timber box beam during and after exposure to fire.

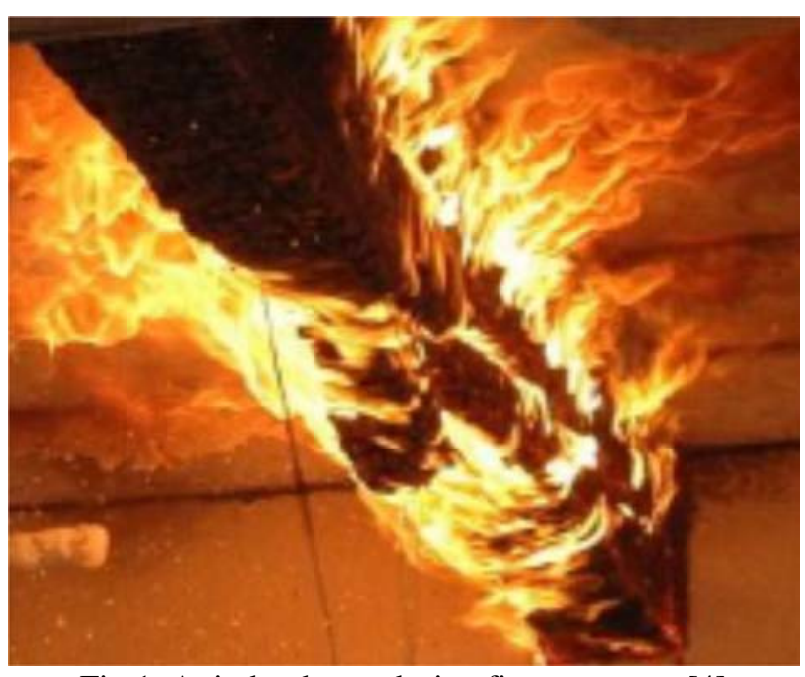

Fig 1. A timber beam during fire exposure. [4]

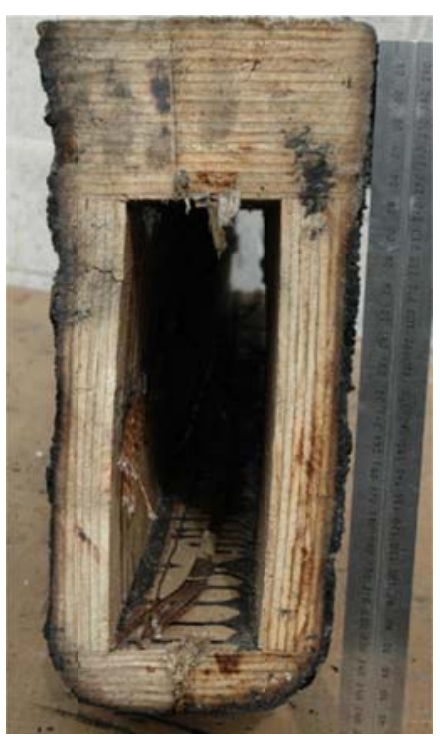

Fig 2. A section of timber box-beam after fire exposure. [4]

Timber structures have been widely researched at the University of Canterbury in recent years. This includes both the structural and fire performance. The research into the fire performance of timber structures includes that by Lane [5] into the ignition, charring and structural performance of Laminated Veneer Lumber (LVL), O’Neill [6] into fire performance of timber-concrete composite floors, Tsai [7] into charring rates of LVL, and Spellman [4, 8] into the fire-performance of post-tensioned timber beams.

\subsection{Post-tensioned timber members}

A significant field of research relating to timber structures involves a new construction technique which utilises post-tensioned timber members. This technique incorporates high-strength steel tendons that are stressed during construction to apply a compressive stress to the member, in order to increase the strength of the member and to tie adjacent members together. Furthermore, this construction technique can lead to other advantages including improved lateral load resistance. While this system was originally developed for use in concrete structures [9] it has also been adopted for use in timber structures [10-12]. Figures 3 and 4 display the Merritt Building and the Massey University College of Creative Arts Building, respectively. These are building that have been recently constructed using post-tensioned timber members.

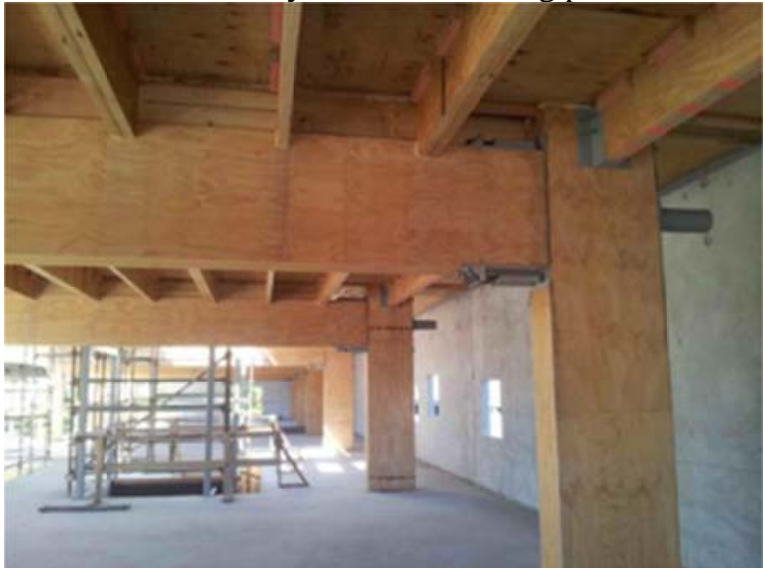

Fig. 3. Merritt Building [13]

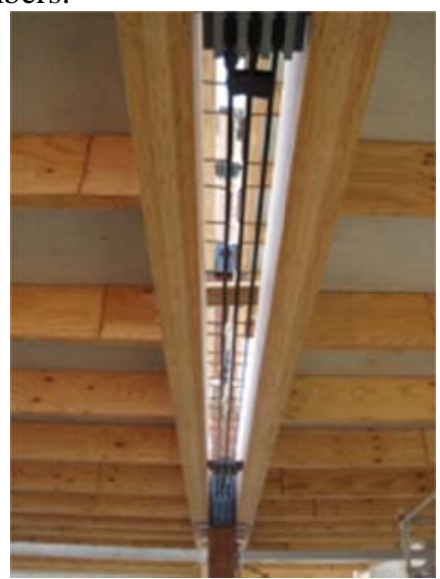

Fig 4. Massey University College of Creative Arts Building [13] 


\subsection{Fire performance of post-tensioned timber}

As post-tensioned timber construction is a very new construction technique very little research has been conducted into its fire performance. Spellman [4, 8] has conducted research into the fire-performance of post-tensioned timber beams. He found that while these members can be designed to achieve sufficient flexural capacity in fire conditions, the shear capacity of these members may not be sufficient to avoid undesirable shear failure modes during fire exposure. It was recommended that shear failure of these members be further researched.

A shear failure mode is more likely to occur in a post-tensioned beam than in a normal beam because the stressed tendon may cause a significant increase in the flexural capacity of a beam while not increasing the shear capacity. As such the ratio of the shear capacity to the flexural capacity of the member may be relatively low compared to a non-post-tensioned beam for the same span and loading. This issue is magnified by the box shape of the member, because box-beams with relatively thin webs may not have excess shear capacity at the location of maximum shear stress.

\section{SIMPLIFIED CALCULATION METHOD}

In order to determine the fire performance of post-tensioned timber box-beams in a post-flashover fire a simplified calculation method has been developed. The method considers the bending, shear and compressive strengths of the beams as well as the combined action for bending and compression. Furthermore, the compressive and tensile stresses in the flanges are also checked. The model determines the demand and capacity of the beam at each time step and therefore is able to predict the time to failure of the beam.

The assumptions used in the simplified calculation method are that:

- $\quad$ the beam is simply supported,

- the tendon is straight and unbonded,

- charring occurs at a uniform rate on all exposed surfaces with no corner rounding,

- the tendon temperature remains at ambient, and

- $\quad$ second order effects are negligible.

The assumption that the tendon temperature remains at ambient is able to be made as the depth of heated timber below the char layer is approximately $35 \mathrm{~mm}$ [2] so the tendon is unlikely to increase in temperature before failure occurs, hence any reduction in post-tensioning force is negligible.

\subsection{Philosophy}

There are two alternative approaches that can be taken when designing a post-tensioned timber box beam. The first approach relies solely on the residual timber members to resist the applied loads during a fire, so the steel post-tensioning components do not need to be protected. The second approach is to protect all of the steel components used in the post-tensioning system, i.e. tendons, anchorages etc. The considerations that should be taken into account when making this decision are discussed below. Table 1 states the advantages and disadvantages of each of the approaches. The methodology used for both approaches are shown below.

If the first approach is used, i.e. the post-tensioning system remains unprotected, the size of the members must be large enough such that the reduced loads in fire conditions can be resisted by the residual timber section only. The residual section size is easily calculated by reducing the total section size by the char depth on surfaces exposed to fire.

The first approach also requires careful consideration of the lateral load resistance of the whole building after the fire. This is especially important if the post-tensioning is an integral component of a lateral load resisting frame. For a multi-storey building, the fire will be contained within a single fire compartment at a single floor level, so the residual lateral load resisting capacity of the structure on the floors unaffected by fire should be able to provide sufficient residual lateral load resistance for the whole building, but this needs to be checked carefully. 
Using the second approach, i.e. protecting the post-tensioning system, will prevent the temperature of the steel components from increasing significantly for the duration of the required fire resistance time. Thus the structural fire safety design can incorporate the contribution of post-tensioning. The timber members must be sized to ensure that there is sufficient residual timber to resist the applied loads and the post-tensioning forces for the duration of the fire.

Table 1. Advantages and disadvantages of two approaches to protecting the post-tensioning.

\begin{tabular}{|c|c|c|}
\hline Approach & Advantages & Disadvantages \\
\hline $\begin{array}{l}1 . \\
\text { No fire protection of } \\
\text { post-tensioning system }\end{array}$ & $\begin{array}{ll}\text { - } & \text { No additional design steps for fire } \\
& \text { design } \\
\text { - } & \text { Faster construction } \\
\text { - } & \text { Reduced cost of protection }\end{array}$ & $\begin{array}{l}\text { Does not utilise existing post- } \\
\text { tensioning capacity }\end{array}$ \\
\hline $\begin{array}{c}2 . \\
\text { Fire-protection of } \\
\text { post-tensioning system }\end{array}$ & $\begin{array}{ll}\text { - } & \text { No reduction in post-tensioning } \\
\text { during fire } \\
\text { - } & \text { Full lateral-load resistance during } \\
\text { fire }\end{array}$ & $\begin{array}{ll}\text { - } & \text { Specific detailing required } \\
\text { - } & \text { Additional cost to protect the } \\
\text { post-tensioning }\end{array}$ \\
\hline
\end{tabular}

\subsection{Methodology}

The methodology detailed below for both approaches is based largely on NZS3603:1993 Timber Structures Standard [14].

\subsubsection{Approach 1 - No Fire Protection of Post-Tensioning System}

The first stage of the process is to determine the section properties for the beam as it chars. It is recommended that a spreadsheet is used so that the calculations can be made at each time step. Three-sided exposure of the beam is assumed, with the top surface concealed from fire exposure. It is assumed that corner rounding has a negligible effect on the performance of the beam so this has not been included. It is recommended that a char rate, $\beta$, of $0.70 \mathrm{~mm} / \mathrm{min}$ with an additional $7.0 \mathrm{~mm}$ zero strength layer be used, as recommended by Eurocode 5 [15]. This isshown in Eq. 1.

$\beta=0.70 \frac{\mathrm{mm}}{\min }$

The section properties of the residual section required for subsequent calculations can then be calculated for each time step by calculating the char depth from Eq. 1 and adding the 7.0mm zero strength layer.

The cross sectional area, $A_{i}$, is calculated using Eq. 2.

$A_{i}=2 t_{w, i} d_{w, i}+w_{f, i}\left(t_{f, t o p, i}+t_{f, b o t t o m, i}\right)$

The shear area, $A_{s, i}$, is calculated using Eq. 3.

$A_{s, i}=\frac{2 t_{w, i} I_{i}}{Q_{i}}$

The first moment of area, $Q_{i}$, is calculated using Eq. 4.

$Q_{i}=t_{f, t o p, i} w_{f, i}\left(\bar{y}_{i}-\frac{t_{f, t o p, i}}{2}\right)+t_{w, i}\left(\bar{y}_{i}-t_{f, t o p, i}\right)^{2}$

The section modulus, $Z_{i}$, is calculated using Eq. 5.

$Z_{i}=\frac{W_{i} D_{i}^{2}}{6}-\frac{w_{h} d_{h}^{2}}{6}$

Due to the complexity of the beam's shape, the second moment of area, $I_{i}$, is calculated using the parallel axis theorem whereby the local second moment of area is calculated for each of the webs and flanges about their centroids and then the centroid of the entire section, as shown in Eq. 6. The neutral axis depth is concurrently calculated using Eq. 7.

$I_{i}=\Sigma I_{c c, x, i}+\Sigma A_{x, i}\left(\bar{y}_{i}-\bar{y}_{x, i}\right)^{2}$

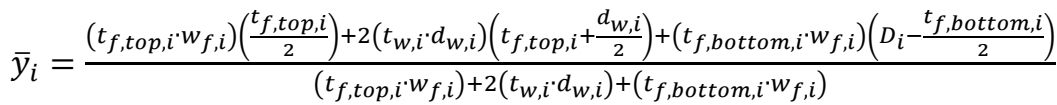


The bending, $\varphi M_{n, i}$, and shear, $\varphi V_{n, i}$, capacities of the beam are then calculated using Equations 8 and 9.

$$
\begin{aligned}
& \varphi M_{n, i}=\varphi k_{1} k_{8} k_{24} f_{b} Z_{i} \\
& \varphi V_{n, i}=\varphi k_{1} f_{s} A_{s, i}
\end{aligned}
$$

Now the bending and shear demands on the beam are calculated. First the uniformly distributed load, q, is determined using an appropriate loading standard, such as AS/NZS 1170.1:2002 [16].

Equations 10 and 11 are then used to calculate the maximum bending, $M^{*}$, and shear, $V^{*}$, demands on the beam at mid-span and at the supports respectively.

$$
\begin{aligned}
M^{*} & =\frac{q L_{B}^{2}}{8} \\
V^{*} & =\frac{q L_{B}}{2}
\end{aligned}
$$

Next Equations 12 and 13 are used to check that the bending and shear capacity of the beam is greater than the respective demands.

$M^{*} \leq \varphi M_{n, i}$

$V^{*} \leq \varphi V_{n, i}$

Finally, the compressive and tensile stresses resulting from the flexural loading are checked in the flanges to ensure crushing or tensile failure does not occur in the extreme fibres. These checks are adopted from the Eurocode 5 [15] design checks for tension and compression.

The mean compressive stress, $\sigma_{f, c, i}$, is checked against the permissible stress, $k_{c} f_{c, i}$, using Eq. 14.

$\sigma_{f, c, i} \leq k_{c} f_{c, i}$

Finally, the mean tensile stress, $\sigma_{f, t, i}$, is checked against the permissible stress, $f_{t, i}$, using Eq. 15.

$\sigma_{f, t, i} \leq f_{t, i}$

\subsubsection{Approach 2 - Fire Protection of Post-Tensioning System}

The same process is used to determine the residual section properties and bending and shear capacities of a timber box beam with a fire protected post-tensioning system, i.e. Equations $1-9$ are repeated. However, the axial capacity of the beam, $\varphi N_{n, i}$, must also be calculated. This is achieved using Eq. 16.

$\varphi N_{n, i}=\varphi k_{1} k_{8} f_{c} A_{i}$

Unlike Approach 1, the maximum bending demand cannot be simply determined using Eq. 10 as the effect of the post-tensioning system must be taken into account. The maximum bending moment, $M_{i}^{*}$, is instead calculated using Eq. 17.

$M_{i}^{*}=M_{q}-M_{P T, i}$

The bending moment that results from the uniformly distributed load, $M_{q}$, is calculated in the same manner as Eq. 10, as shown in Eq. 18.

$M_{q}=\frac{q L_{B}^{2}}{8}$

The bending moment that results from the post-tensioning system, $M_{P T, i}$, is calculated using Eq. 19.

$M_{P T, i}=e_{i} \cdot P T$

The eccentricity of the tendon, $e_{i}$, is calculated using Eq. 20.

$e_{i}=e_{0}+\Delta \bar{y}_{i}-\delta_{i}$ 
As the beam chars the neutral axis depth of the section changes because the beam is no longer symmetrical about the horizontal axis. This changes the eccentricity between the tendon and the neutral axis. This change in neutral axis depth, $\Delta \bar{y}_{i}$, is taken into account in Eq. 21.

$\Delta \bar{y}_{i}=\bar{y}_{0}-\bar{y}_{i}$

When the beam deflects during the fire exposure, the straight tendon remains in its original position (as the tendon is unbonded along its span), so the mid-span deflection must be considered when calculating the eccentricity. The deflection of the beam, $\delta_{i}$, is calculated using Eq. 22.

$\delta_{i}=\delta_{q, i}+\delta_{V, i}-\delta_{P T, i}$

The calculation method considers the elastic deflection caused by gravity loads, $\delta_{q, i}$, elastic shear deflection, $\delta_{V, i}$, and the hogging deflection due to the post-tensioning system, $\delta_{P T, i}$. All deflections are calculated for the residual section at midspan.

Equation 23 is used to calculate the elastic deflection caused by gravity loads.

$\delta_{q, i}=\frac{5 \cdot q \cdot L_{B}^{4}}{384 \cdot E \cdot I_{i}}$

Equation 24 is used to calculate the elastic shear deflection.

$\delta_{V, i}=\frac{q \cdot L_{B}^{2}}{8 \cdot G \cdot A_{s, i}}$

Equation 25 is used to calculate the hogging deflection due to the post-tensioning system. As Eq. 25 requires the eccentricity to be known, an iterative calculation is required.

$\delta_{P T, i}=\frac{e_{i} \cdot P T \cdot L_{B}^{2}}{8 \cdot E \cdot I_{i}}$

Equation 11 is again used to calculate the shear strength at the point of maximum shear force.

The axial demand on the beam, $N^{*}$, is taken from the post-tensioning force, as determined in the structural design of the beam. This is demonstrated in Eq. 26.

$N^{*}=\mathrm{PT}$

Next Equations 12 and 13 are again used to check that the bending and shear capacity of the beam is greater than the respective demands. The axial capacity of the section is also checked using Eq. 27.

$N^{*} \leq \varphi N_{n}$

A combined bending-compression check is also performed. This is shown in Eq. 28.

$\frac{N^{*}}{\emptyset N_{n}}+\frac{M^{*}}{\emptyset M_{n}} \leq 1.0$

Equations 14 and 15 are again used to check the compressive and tensile stresses in the top and bottom flanges.

\subsection{Results}

Using a spreadsheet to perform these calculations allows the failure time for each of the different modes to be calculated, and following this, a prediction of the mode of failure can be made. This is very useful in order to determine whether an undesirable shear failure is likely to occur in post-tensioned box beams. Furthermore, the parameters that lead to an increased likelihood of shear failure occurring can be determined and recommendations made so that designers can avoid this from occurring.

It is recommended that a ratio of demand versus capacity is calculated for each strength check. If the ratio exceeds 1.0 failure is predicted to occur. As this is calculated at each time step, this can then be graphically represented to clearly illustrate the most likely failure mode as well as when failure is predicted to occur. Examples of these graphs are given in Section 3.2. 


\section{EXAMPLE CALCUATIONS}

Two beam geometries have been considered and used to demonstrate the simplified calculation method described above. The beam geometries are based on typical beams designed for a seismic area and a non-seismic area and were developed during the structural design process. The designs were taken from the Post-Tensioned Timber Building Design Guide [13].

While there is no difference in the methodology used for the fire design for the "seismic" and "gravity" beams, there is however a difference in the behaviour of the different beams, due to the significantly different section geometries. These differences are detailed below.

\subsection{Calculation inputs}

Table 2 displays the beam parameters used in the calculation method prior to taking into account the effects of fire.

Table 2. Beam parameters.

\begin{tabular}{|l|c|c|c|c|c|c|c|c|c|}
\hline Beam & Span & $\mathrm{G}^{*}$ & $\mathrm{Q}^{*}$ & $\mathrm{D}$ & $\mathrm{w}_{\mathrm{f}}$ & $\mathrm{t}_{\mathrm{f}}$ & $\mathrm{t}_{\mathrm{w}}$ & $\mathrm{e}_{0}$ & $\mathrm{PT}$ \\
\hline & $\mathrm{m}$ & $\mathrm{kN} / \mathrm{m}$ & $\mathrm{kN} / \mathrm{m}$ & $\mathrm{mm}$ & $\mathrm{mm}$ & $\mathrm{mm}$ & $\mathrm{mm}$ & $\mathrm{mm}$ & $\mathrm{kN}$ \\
\hline 1. Seismic & 5.3 & 27.6 & 24.0 & 650 & 441 & 230 & 126 & 0 & 417 \\
\hline 2. Gravity & 8.6 & 29.6 & 24.0 & 800 & 315 & 90 & 63 & 280 & 935 \\
\hline
\end{tabular}

Figures 5 and 6 show the cross section of the seismic and gravity beams prior to fire exposure, respectively.

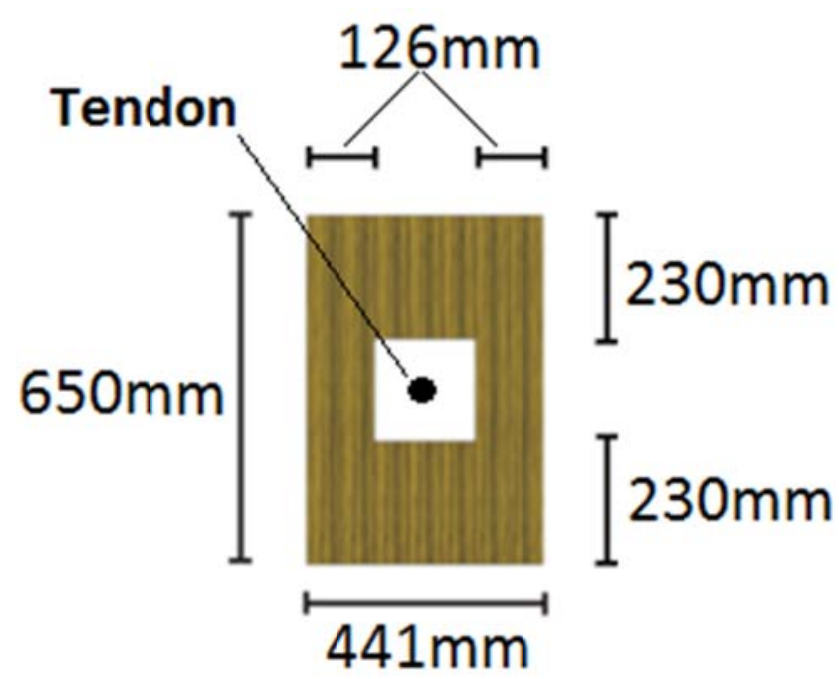

Fig. 5. Cross section of seismic beam prior to fire exposure.

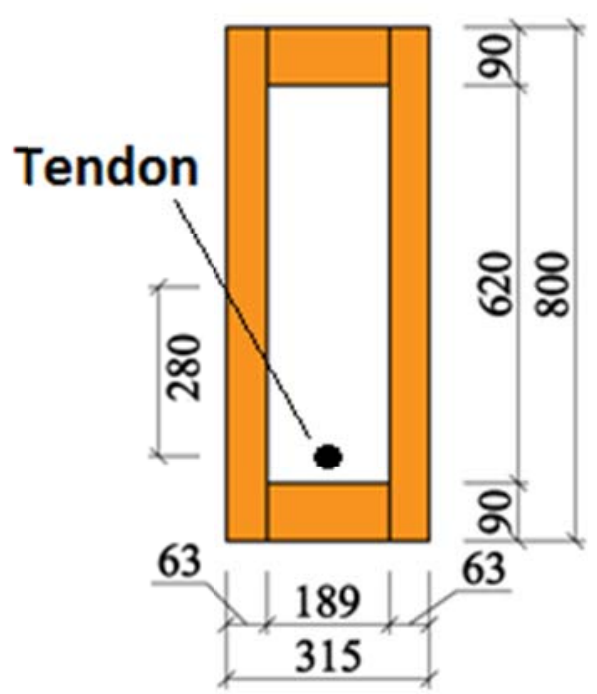

Fig. 6. Cross section of gravity beam prior to fire exposure.

The timber properties used in the calculations are shown in Table 3.

Table 3. Timber properties.

\begin{tabular}{|l|c|c|c|c|c|c|}
\hline Property & $\mathrm{f}_{\mathrm{c}}$ & $\mathrm{f}_{\mathrm{t}}$ & $\mathrm{f}_{\mathrm{b}}$ & $\mathrm{f}_{\mathrm{s}}$ & $\mathrm{E}$ & $\mathrm{G}$ \\
\hline Input value & $45 \mathrm{MPa}$ & $30 \mathrm{MPa}$ & $48 \mathrm{MPa}$ & $6 \mathrm{MPa}$ & $11 \mathrm{GPa}$ & $550 \mathrm{MPa}$ \\
\hline
\end{tabular}




\subsection{Results}

The failure times and modes for both beams, using both approaches, are shown in Table 4.

Table 4. Beam parameters.

\begin{tabular}{|l|l|l|l|}
\hline Beam & Post-Tensioning & Failure Time & \multicolumn{1}{|c|}{ Failure Mode } \\
\hline \multirow{2}{*}{ 1. Seismic } & Unprotected & $141 \mathrm{~min}$ & Shear \\
\cline { 2 - 4 } & Protected & $141 \mathrm{~min}$ & Shear \\
\hline \multirow{2}{*}{ 2. Gravity } & Unprotected & $31 \mathrm{~min}$ & Flexural Tensile Stress \\
\cline { 2 - 4 } & Protected & $47 \mathrm{~min}$ & Shear \\
\hline
\end{tabular}

The failure time for the seismic beam is much greater than for the gravity beam. This is simply because the seismic beam has a far more squat and chunky cross section with less surface area exposed to fire. This results in a smaller volume of timber being charred in the seismic beam and so a much longer time to failure is predicted.

Shear failure is predicted to occur in the seismic beam regardless of whether the post-tensioning system is protected or not. This clearly shows that shear failure is a real possibility to occur in timber box beams, with or without a post-tensioning system. As such, further work should be completed to identify when this will occur and how to avoid this undesirable failure mode.

Protecting the post-tensioning system in the seismic beam does not increase the predicted failure time. This is because the straight unbonded tendon, as assumed in the calculation method, will not carry any shear forces and so will not increase the shear capacity. However a draped tendon will increase the shear capacity of the beam. Draped tendons are discussed in more detail in Section 4.1.

In the gravity beam the failure mode changes from a flexural tensile stress failure to a shear failure when the post-tensioning system is protected. This is because the axial force applied by the post-tensioning reduces flexural tensile stress across the whole member, thus reducing the flexural tensile stress in the bottom flange below critical levels until after a shear failure is predicted to occur. The failure time increases by more than $50 \%$ when the post-tensioning system is protected.

Figures 7 to 10 detail the relative magnitudes of the various demands placed on the beams.

Seismic beam: Figures 7 and 8 clearly show that the relative shear demand is far greater than any other component for the seismic beam. As the calculations made assume a straight tendon, and hence shear capacity is not affected, the influence of the posttensioning system is effectively irrelevant for this beam. While the post-tensioning system does reduce tensile stress (while increasing compressive stress) across the member this effect is largely irrelevant as shear demand dictates the behaviour of the beam. Also, adding the axial force results in a combined bending and compression demand greater than bending by itself when the post-tensioning system is not protected. Again this consequence is largely irrelevant as shear demand dictates behaviour of the seismic beam.

It should be noted that the initial design of this beam did not consider calculations for fire resistance, and the predicted failure time of 141 minutes is far greater than the fire resistance required for structural frames in New Zealand or Australia.

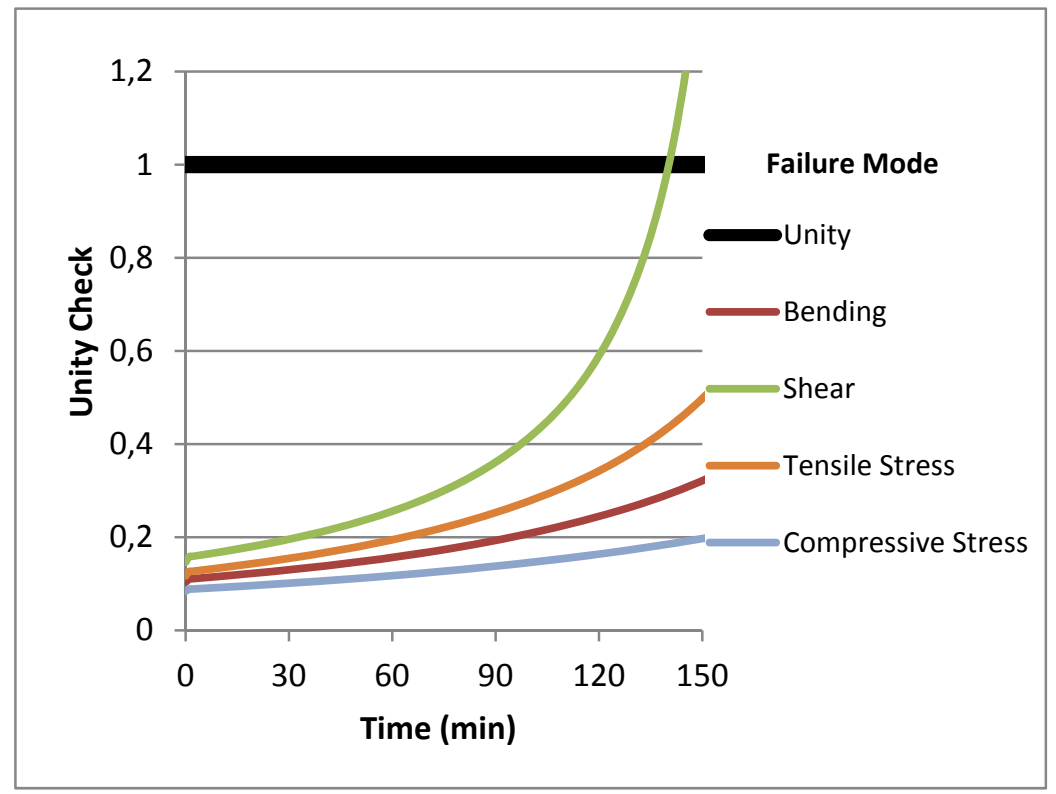

Fig. 7. Unity check for seismic beam without protected post-tensioning system. 


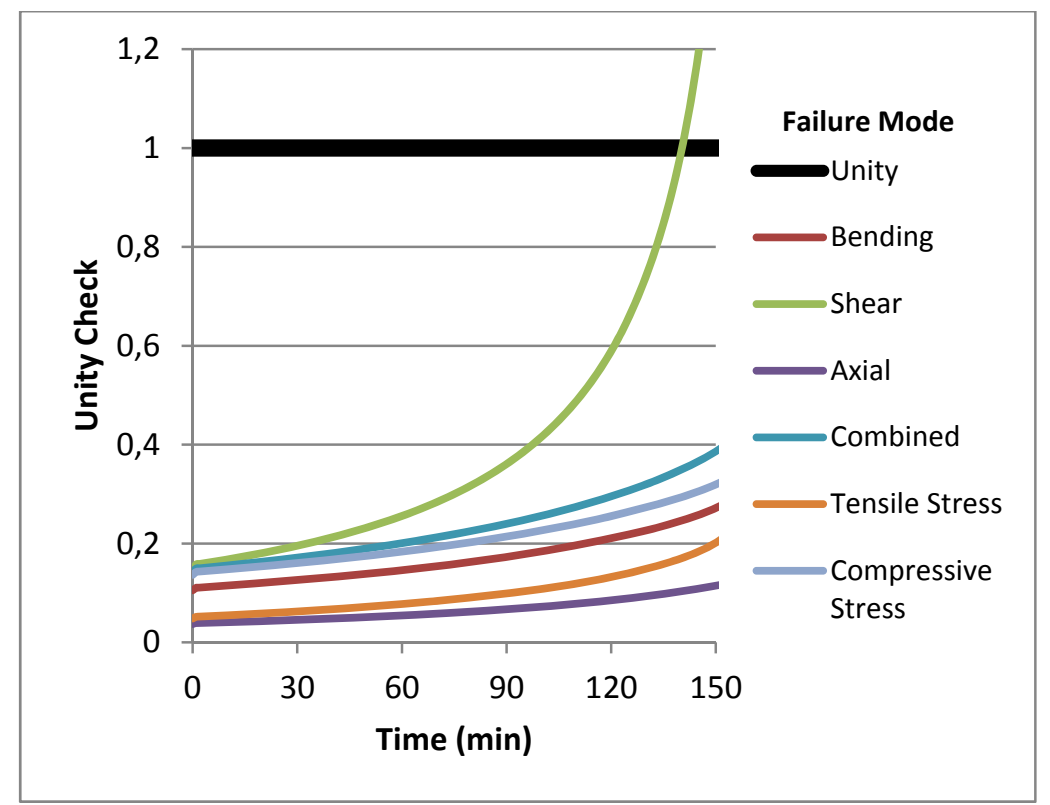

Fig. 8. Unity check for seismic beam with protected post-tensioning system.

Gravity beam: As noted above there is a significant difference in the performance of the gravity beam when the approach to protect the post-tensioning system is used compared to when the post-tensioning system is not protected, as seen in Figures 9 and 10. The failure time increases by more than $50 \%$ and the failure mode changes from a tensile stress failure to a shear failure. These changes are caused by the introduction of the axial force, which, as previously stated, decreases the tensile stress across the member while it does not affect the shear demand. This clearly shows that protecting the post-tensioning system can have significant benefits for the fire design of a timber box beam with thin webs.

While tensile stress, shear and bending failures are all predicted to occur within 30 minutes of each other when the post-tensioning system is unprotected, shear failure is the only likely failure mode for when the post-tensioning system is protected. As such, if shear failure is to be completely avoided it may be advisable to either not protect the post-tensioning system or increase the shear capacity of the beam by utilising a draped tendon. The considerations of using a draped tendon are discussed in more detail in Section 4.1.

The relative bending demand significantly decreases when the post-tensioning system is protected. While the beam was not predicted to fail in bending in the unprotected case, the introduction of the post-tensioning is likely to prevent any form of bending failure from occurring in the beam during fire exposure. Interestingly the compressive stress slightly decreases, despite the introduction of the axial compression force from the post-tensioning system. This is a result of the reduced maximum bending demand caused by the introduction of the post-tensioning.

It should be noted that this beam with thin webs, which is an optimum design for gravity loads, has a very low level of fire resistance, such that a required fire resistance of 60 minutes or more will require re-design of the beam with much heavier timber components.

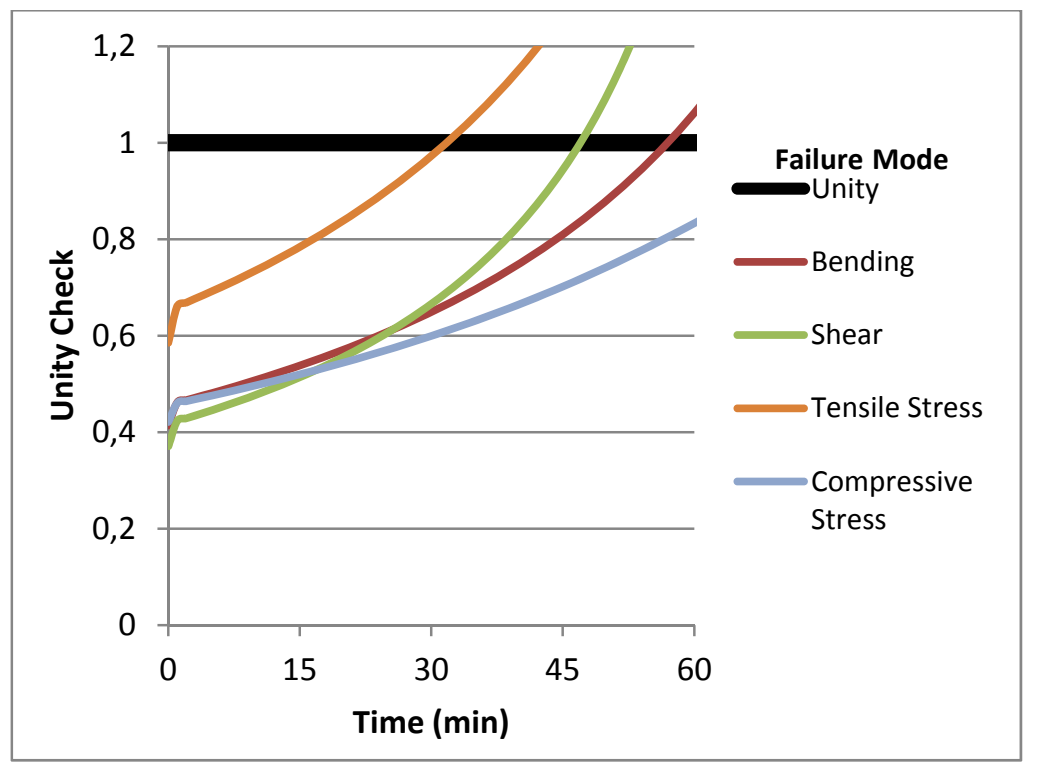

Fig. 9. Unity check for gravity beam without protected post-tensioning system. 


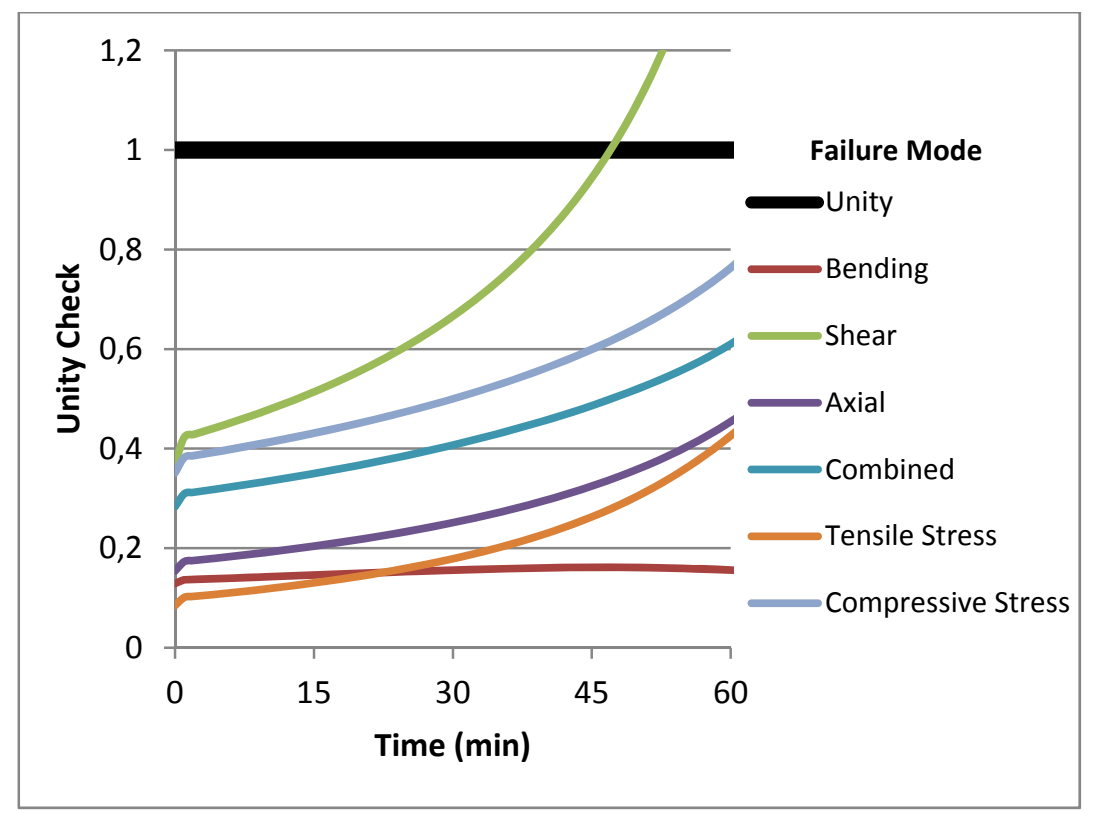

Fig. 10. Unity check for gravity beam with protected post-tensioning system.

\section{OTHER DESIGN CONSIDERATIONS}

It has been assumed that the beams considered above are simply-supported with a straight tendon profile. However, it is likely that only a few post-tensioned timber box beams will fit into this category, with many more utilising either draped tendons or momentresisting connections into a structural frame. The effects that these changes would have on the calculation method are described below. Other considerations that should be taken into account in the design of these beams are also discussed.

\subsection{Draped tendons}

The design of a beam with a draped tendon will follow a similar methodology as to that detailed above; the difference in the design of a beam with a draped tendon will arise when calculating the shear demand.

The draped tendon will result in a vertical component of the post-tensioning force in the end regions of the beam. This will have the effect of decreasing the shear demand on the beam in the areas where the tendon is inclined. As such, additional calculations can be completed to include the effect of the draped tendon profile, potentially producing a more efficient design. However, the effect of the draped tendon can be conservatively ignored and the calculations detailed above can be followed.

The calculation to determine the eccentricity of the tendon will also change for a draped tendon. As the tendon is fixed in place by deviators the tendon will deflect with the beam. Therefore the deflection component of the equation, $\delta_{i}$, to calculate the eccentricity, $e_{i}$, can be ignored, as shown in Eq. 29.

$e_{i}=e_{0}+\Delta \bar{y}_{i}$

If the post-tensioning system is not protected there will be no difference in the design of a beam with a draped tendon compared to a straight tendon.

\subsection{Beam within a frame system}

It has been assumed in the calculations above that the beam is simply supported. As such the negative moments at the ends of the beams, which would decrease the demand on the beam, are ignored. Therefore, if the beam is shown to be satisfactory for the simply supported case it will also be satisfactory if the beam is part of a moment-resisting frame system. If the beam is not simply supported, additional calculations can be completed to include the effect of the frame system, which could produce a more efficient design.

\subsubsection{Miscellaneous design considerations}

The designer of the beam system must check the fire resistance of any horizontal or vertical penetrations through the beam.

Checks should be made on the size and residual bearing area of any corbels and timber seating details, such that adequate bearing remains after a fire event.

The lateral stability of the entire building needs to be considered. If a fire was to completely weaken or destroy a primary beam on one level of the structure, the entire building should have enough remaining strength to withstand lateral actions, excluding seismic actions. 


\section{FUTURE RESEARCH}

The research into the fire performance of post-tensioned timber box beams is on-going. As such, a number of areas will be looked into in more detail in the coming months. The likely areas of further research are discussed below.

\subsection{Checking validity of assumptions}

The validity of all assumptions will be checked. While it is assumed that corner rounding and second order effects will have a minimal impact on the result produced by the calculation method, these will be included in a future version of the calculation methodology to ensure that the assumptions are valid. If it is deemed necessary second-order effects will be introduced into the model at a later stage. This may be achieved by including an adjustment factor to reasonably accurately account for corner rounding or second order effects.

\subsection{Detailed research into conditions that lead to shear failure occurring}

Detailed research into conditions that lead to shear failures will be completed. This will be achieved by considering a wide range of beam geometries and properties, including spans, cross section dimensions, timber strengths, post-tensioning forces and eccentricities. It is hoped that the parameters that have a large influence on whether shear failure occurs, or the range of values for the various parameters that result in shear failure, can be identified. The results of this research will then be published in order to provide guidance to designers in order to avoid shear failure of post-tensioned timber box beam in fire conditions.

\subsection{Full scale testing of beams}

A series of full scale tests will be conducted in order to verify the proposed calculation method. The first stage of testing will involve the structural testing of post-tensioned timber box beams at ambient temperatures, at the University of Canterbury, New Zealand. Various section sizes will be used to verify the calculation method of shear strength of box-beams for a range of beam geometries and other parameters. Full scale testing in a furnace will then be conducted at the Building Research Association New Zealand laboratory in Wellington, New Zealand to further verify the proposed calculation method in fire conditions. The furnace temperature will follow the ISO 834 specification [17].

\section{CONCLUSION}

A simplified calculation method for the fire performance of post-tensioned timber box beams has been developed. The method considers the bending, shear, compressive and combined bending and compressive strengths of the beam. Furthermore the tensile and compression stresses in the flanges of the beam are also checked. The method can be used to determine the failure time and failure mode of the beam during exposure to fire.

From the early use of the model, the shear performance of these beams has been highlighted as a potential design issue. This is an area that requires further research. Continual development of the method, including the detailed research into shear performance, is on-going.

\section{REFERENCES}

[1] SP Technical Research Institute of Sweden, Fire safety in timber buildings. Technical guideline for Europe, 2010, SP Technical Research Institute of Sweden: Stockholm, Sweden.

[2] Buchanan, A.H., Structural Design for Fire Safety, 2001, Chichester, England: John Wiley \& Sons Ltd.

[3] Buchanan, A.H., Timber Design Guide. 3rd ed, 2007, Wellington, New Zealand: New Zealand Timber Industry Federation Inc.

[4] Spellman, P.M., The Fire Performance of Post-Tensioned Timber Beams, in Department of Civil and Natural Resources Engineering, 2012, University of Canterbury: Christchruch, New Zealand.

[5] Lane, W.P., Ignition, Charring and Structural Performance of Laminated Veneer Lumber, in Department of Civil and Natural Resources Engineering, 2005, University of Canterbury: Christchruch, New Zealand.

[6] O'Neill, J., The Fire Performance of Timber-Concrete Composite Floors, in Department of Civil and Natural Resources Engineering, 2008, University of Canterbury: Christchruch, New Zealand.

[7] Tsai, W.H., Charring Rates for Different Cross Sections of Laminated Veneer Lumber (LVL), in Department of Civil and Natural Resources Engineering, 2010, University of Canterbury: Christchruch, New Zealand.

[8] Spellman, P.M., et al., Design of Post-Tensioned Timber Beams for Fire Resistance, in 7th international Conference on Structures in Fire, M. Fontana, A. Frangi, and M. Knobloch, Editors. 2012, ETH Zurich: Zurich, Switzerland.

[9] Priestley, M.J.N., et al., Preliminary Results and Conclusions from the PRESSS Five-story Precast Concrete TestBuilding. PCI Journal, 1999. 44: p. 42-67.

[10] Newcombe, M., Seismic Design of Multistory Post-Tensioned Timber Buildings, 2007, University of Pavia: Pavia, Italy.

[11] Palermo, A., et al., Seismic Design of Multi-Storey Buildings using Laminated Veneer Lumber in New Zealand Society of Earthquake Engineering Conference, 2005: Wairaki, New Zealand. 
[13] Pampanin, S., A. Palermo, and A.H. Buchanan, Post-Tensioned Timber Buildings Design Guide, 2013, Canterbury, New Zealand: University of Canterbury.

[14] Standards New Zealand, NZS 3603:1993 Timber Structures Standard, 1993, Standards New Zealand: Wellington, New Zealand.

[15] European Commison, Eurocode 5: Design of Timber Structures, 2004, European Committee for Standardization: Brussels, Belgiuum.

[16] Standards New Zealand, NZS 1170.1:2002 Structural design Actions, in Part 1: Permanent, imposed and other actions, 2002, Standards New Zealand: Wellington, New Zealand.

[17] ISO, ISO 834-1975 Fire resistance tests - elements of building construction, 1975, International Organization for Standarization. 